DOI 10.37882/2223-2982.2020.12-3.20

\title{
ФОРМИРОВАНИЕ ЦЕННОСТЕЙ НАУЧНОГО ПОЗНАНИЯ ПОСРЕДСТВОМ УЧЕБНО-ИССЛЕДОВАТЕЛЬСКОЙ ДЕЯТЕЛЬНОСТИ УЧАЩИХСЯ (НА ПРИМЕРЕ БИОЛОГИИ И ЭКОЛОГИИ)
}

\section{FORMATION OF VALUES OF SCIENTIFIC KNOWLEDGE THROUGH EDUCATIONAL AND RESEARCH ACTIVITIES OF PUPULS (ON THE EXAMPLE OF BIOLOGY AND ECOLOGY)}

A. Semenov A. Yaitsky

Summary: The article is devoted to the problem of forming the values of scientific knowledge in secondary school pupils. As the main tool for solving this problem, the authors define the technology of organizing educational and research activities. The work is performed using traditional methods of pedagogical research such as the study of methodological literature, the method of theoretical analysis and synthesis, the method of designing educational and research activities of pupils. The article presents the results of educational research on the formation of scientific knowledge values using various forms of teaching biology and ecology (lesson, excursion, homework, required extracurricular work and optional extracurricular work). Educational and research activities of pupils are designed in the logic of scientific research and include motivational-target, content, procedural and performanceevaluation components. The materials of the article can be used by schoolteachers, as well as methodologists-biologists for the purpose of training future subject teachers.

Keywords: general education; biology training; ecology training; upbringing; values of scientific knowledge; educational and research activities.

\section{Семенов Александр Алексеевич}

к.б.н., дочент, ФГБОУ ВО «Самарский государственный сочиально-педагогический университет»

semenov@sgspu.ru

Яичкий Андрей Степанович

старший преподаватель, ФГБОУ ВО «Самарский государственный сочиально-педагогический

университет»

yaitsky@sgspu.ru

Аннотация: Статья посвящена проблеме формирования ценностей научного познания у учащихся общеобразовательных организаций. В качестве основного инструмента решения данной проблемы авторами определена технология организации учебно-исследовательской деятельности. Работа выполнена с использованием традиционных методов педагогических исследований, таких как изучение методической литературы, метода теоретического анализа и синтеза, метода проектирования учебно-исследовательской деятельности учащихся. В статье приведены методические паспорта учебных исследований по формированию ценностей научного познания при использовании различных форм обучения биологии и экологии (урок, экскурсия, домашняя работа, внеурочная работа и внеклассная работа). Учебно-исследовательская деятельность учащихся спроектирована в логике научного исследования и включает в себя мотивационно-целевой, содержательный, процессуальный и результативно-оценочный компоненты. Материалы статьи могут быть использованы учителями общеобразовательных организаций, а также методистами-биологами с целью подготовки будущих учителей-предметников.

Ключевые слова: общее образование; обучение биологии; обучение экологии; воспитание; ценности научного познания; учебно-исследовательская деятельность.

\section{Введение}

$\mathrm{B}$ настоящее время общеобразовательные организации Российской Федерации завершают переход на стандарты второго поколения - федеральные государственные образовательные стандарты общего образования (ФГОС ОО) [1]. Разработка и введение школьных стандартов нового поколения связаны с социально-экономическими преобразованиями в нашей стране, а также с общемировыми тенденциями перехода от индустриального общества к информационному. Стратегической задачей российского образования в настоящее время является обновление его содержания, методов обучения и достижения на этой основе нового качества его результатов. В центр государственной образовательной политики поставлена личность обучающегося. Развитие личности - смысл и цель современного образования [2].

Одним из направлений воспитательной работы в системе общего образования является формирование у учащихся ценностей научного познания, которые предполагают ориентацию в деятельности на современную систему научных представлений о важнейших закономерностях развития человека, природы и общества, взаимосвязях человека с природной и социальной средой; овладение языковой и читательской культурой как средством познания мира; усвоение основных навыков ис- 
следовательской деятельности, установку на осмысление опыта, наблюдений, поступков, а также стремление совершенствовать пути достижения индивидуального и коллективного благополучия [3].

Естественнонаучные предметы, в том числе биология и экология, как никакие другие, призваны формировать научное мировоззрение и ценности научного познания. Эта проблема не нова. Она находит отражение в работах многих методистов-биологов. Среди них следует отметить Н.Д. Андрееву [4], И.Ю. Азизову [5], М.И. Морозову [6], Н.С. Постнову [7], С.С. Рябову [8], Н.Г. Семенову [9], Л.А. Чекалову [10].

Результативность формирования ценностей научного познания зависит от выбора форм, методов, средств обучения и воспитания, а также образовательных технологий. На наш взгляд, наиболее действенным способом решения данной проблемы является вовлечение учащихся в учебно-исследовательскую деятельность [11].

Методические подходы к организации учебно-исследовательской деятельности учащихся по биологии и экологии рассматриваются в работах Н.Д. Андреевой [12; 13], Н.Г. Бобровой [14; 15], Б.В. Всесвятского [16], Я.С. Ковшар [17], И.В. Наливайко [18], А.А. Семенова [19], С.В. Суматохина [20; 21], Е.В. Тягловой [22], В.П. Ясюка [23].

Несмотря на существенную степень разработанности проблемы формирования ценностей научного познания, она, по-прежнему, остается актуальной и требует более эффективных способов и подходов к ее реализации.

Ниже приведены методические паспорта учебных исследований по формированию ценностей научного познания при использовании различных форм обучения биологии и экологии, таких как урок, экскурсия, домашняя работа, внеурочная работа и внеклассная работа.

\section{***}

Учебно-исследовательская деятельность учащихся по биологии и экологии организуется с учетом логики научного исследования и включает в себя мотивационно-целевой, содержательный, процессуальный и результативно-оценочный компоненты [19].

Урок - основная форма обучения, при которой учитель в течение точно установленного времени (40-45 минут) руководит коллективной учебной и иной деятельностью постоянной группы учащихся (класса) [24]. Уроки биологии и экологии богаты лабораторными и практическими работами, в рамках которых можно провести учебные мини-исследования. В качестве примера рассмотрим методику организации учебно-исследова- тельской деятельности в рамках лабораторной работы по теме «Ферменты слюны и их действие на крахмал».

\section{Мотивашионно-шелевой компонент}

Цель исследования: доказательство наличия ферментов в слюне и их действия на крахмал.

Объект исследования: ферменты слюны.

Предмет исследования: действие ферментов слюны на крахмал.

Гипотеза исследования: в слюне содержатся ферменты, которые расщепляют крахмал.

\section{Содержательный компонент}

Основные понятия: слюна, ферменты, пищеварение, ротовая полость.

\section{Прошессуальный компонент}

Методы исследования: эксперимент.

Материал и оборудование: накрахмаленные кусочки марли (бинта), стерильные ватные палочки, стакан с водой, чашка Петри, стакан с йодной водой.

Место проведения: кабинет биологии.

Форма организации: парная.

Порядок работы: 1. Возьмите кусочек накрахмаленной марли. Смочите стерильную ватную палочку слюной. Нанесите слюну на кусочек марли и зажмите его на несколько секунд между ладонями. 2. Опустите кусочек марли в йодную воду. 3. Повторите эксперимент еще раз, но вместо слюны смочите ватную палочку водой.

\section{Результативно-ошеночный компонент}

Форма предъявления результата: таблица «Свойства ферментов слюны» [25]:

\begin{tabular}{|c|c|c|}
\hline Условия эксперимента & Результаты эксперимента & Выводы \\
\hline & & \\
\hline
\end{tabular}

Выводы: 1. Слюна содержит ферменты, расщепляющие крахмал. 2. Вода не расщепляет крахмал. Наличие в слюне ферментов, расщепляющих крахмал, доказано. Гипотеза подтверждена.

Экскурсия - важная форма обучения биологии и экологии, проводится с классом или группой учащихся, вне общеобразовательной организации с учебно-познавательной целью при передвижении от объекта к объ- 
екту в их естественной среде или искусственно созданных условиях [26]. Ключевым этапом экскурсии является самостоятельная работа учащихся, в рамках которой можно организовать учебное исследование. Например, экскурсия в зоологический музей им. Д.Н. Флорова Самарского государственного социально-педагогического университета (СГСПУ) по теме «Приспособления животных к среде обитания».

\section{Мотивашионно-шелевой компонент}

Цель исследования: выявление адаптаций у животных к среде обитания.

Объект исследования: жираф, дельфин-белобочка, крот, бычий цепень.

Предмет исследования: адаптации животных к определенным средам обитания.

Гипотеза исследования: у животных в ходе эволюции возникают приспособления к среде обитания.

\section{Содержательный компонент}

Основные понятия: среды обитания, адаптации, водная среда обитания, наземно-воздушная среда обитания, почвенная среда обитания, организм как среда обитания.

\section{Прошессуальный компонент}

Методы исследования: распознавание и определение объектов.

Материал и оборудование: чучела жирафа и крота, макет дельфина-белобочки, влажный препарат бычьего цепня.

Место проведения: зоологический музей им. Д.Н. Флорова СГСПу.

\section{Форма организации: групповая.}

Порядок работы: рассмотрите экспонаты зоомузея жирафа, дельфина-белобочку, крота и бычьего цепня, определите их среды обитания и адаптации к этим средам.

\section{Результативно-оченочный компонент}

Форма предъявления результата: ответы на вопросы: 1. В каких средах обитают жираф, дельфин-белобочка, крот и бычий цепень? 2. Какие у них есть адаптации к жизни в той или иной среде обитания?

Выводы: 1. Жираф живет в наземно-воздушной среде обитания. У него есть конечности наземного типа, сложные покровы тела (кожа с шерстью), дышит с помощью легких атмосферным воздухом. 2. Дельфин-белобочка живет в воде. У него редуцированы конечности (превратились в плавники), редуцирован тазовый пояс, обтекаемая форма тела (рыбья), ноздри переместились на темя и закрываются клапанами. 3. Крот живет в почве. У него валикообразная (цилиндрическая) форма тела, слабо развито зрение, хорошо развито обоняние, редуцированные ушные раковины, передние конечности копательного типа с большими когтями, мех легко ложится в любом направлении. 4. Бычий цепень живет в кишечнике у человека. На головке есть крючки для удержания в теле хозяина, сложные покровы тела, препятствующие перевариванию, питательные вещества поглощает всей поверхностью тела, нет пищеварительной системы, не развиты органы чувств, анаэробный тип дыхания [27].

Внеурочная работа - организуется с целью выполнения вне урока обязательных, связанных с изучением курса практических работ по индивидуальным и групповым заданиям учителя. К внеурочным работам, например, относятся летние задания. Учащимся можно предложить выполнить в качестве летнего задания учебное исследование по теме «Влияние прищипки верхушечной почки на урожайность огурцов».

\section{Мотивационно-шелевой компонент}

Цель исследования: изучение влияния прищипки верхушечной почки на урожайность огурцов.

Объект исследования: огурцы сорта «Феникс».

Предмет исследования: влияние прищипки верхушечной почки на урожайность огурцов сорта «Феникс».

Гипотеза исследования: прищипка верхушечной почки усилит рост и развитие огурцов, а следовательно, и их урожайность.

\section{Содержательный компонент}

Основные понятия: сельскохозяйственные растения, агротехника выращивания огурцов, прищипка, верхушечная почка, урожайность.

\section{Прошессуальный компонент}

Методы исследования: эксперимент, наблюдение.

Материал и оборудование: сорт огурцов «Феникс», садовый инвентарь.

Место проведения: учебно-опытный участок (садовый участок). 
Форма организации: индивидуальная.

Порядок работы: 1. Заложите эксперимент и проведите наблюдение за огурцами сорта «Феникс», выращенными с прищипкой верхушечной почки и без нее. 2. Выясните, как изменяются рост и развитие растений после удаления над четвертым настоящим листом верхушечной почки. Контролем служат растения без такой прищипки. 3. Отметьте, где раньше начинается рост боковых побегов, цветение, образование плодов; где больше (по массе) урожай. 4. Проследите, где появляются первые цветки - на главном или боковых побегах; каково их строение; каких цветков (пестичных или тычиночных) больше на этих побегах. 5. Продумайте, как пыльца попадает на рыльца пестиков; сколько времени проходит от опыления цветка до образования плода (зеленца) и до образования семян; зависит ли количество плодов и быстрота их роста от температуры воздуха [28].

\section{Результативно-оченочный компонент}

Форма предъявления результата: письменный отчет.

Вывод: прищипка верхушечной почки способствовала образованию дополнительных боковых побегов, что сделало растения более густыми и повысило урожайность в 2 раза по сравнению с контрольным образцом.

Внеклассная работа - имеет добровольный характер, проводится по желанию учащихся во внеурочное время с целью развития их интереса к изучению биологии и экологии. Она бывает индивидуальной, групповой (кружок) и массовой [26]. В рамках индивидуальной внеклассной работы интересующимся предметом учащимся можно предложить выполнить учебное исследование по теме «Влияние физической нагрузки на работоспособность сердца и артериальное давление».

\section{Мотивационно-челевой компонент}

Цель исследования: выявление влияния физической нагрузки на работоспособность сердца и артериальное давление.

Объект исследования: сердечно-сосудистая система человека.

Предмет исследования: влияние физической нагрузки на работу сердечно-сосудистой системы человека.

Гипотеза исследования: физические упражнения влияют на работоспособность сердечной мышцы и артериальное давление. Физическая культура способствует повышению выносливости и тренированности сердца, стабильности артериального давления.

\section{Содержательный компонент}

Основные понятия: сердечно-сосудистая система человека, сосуды, артерии, вены, капилляры, сердце, строение сердца, работа сердца, круги кровообращения, артериальное давление, пульс.

\section{Прошессуальный компонент}

Методы исследования: измерение артериального давления, подсчет пульса.

Материал и оборудование: тонометр, секундомер.

Место проведения: кабинет биологии, лаборантская.

Форма организации: индивидуальная.

Порядок работы: 1. Определите величину артериального давления и частоту сердечных сокращений (ЧСС) у своих одноклассников в состоянии покоя и после дозированной нагрузки (10 приседаний) с помощью тонометра. 2. Полученные результаты занесите в таблицу:

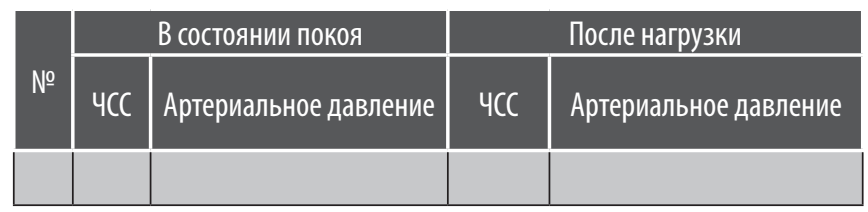

3. Для каждого ученика вычислите показатель изменения ЧСС между данными в состоянии покоя и после дозированной нагрузки. Для этого из величины пульса после нагрузки вычтите величину пульса в состоянии покоя, разделите полученный результат на величину пульса в состоянии покоя и умножьте на 100\%. Если 10 приседаний вызвали учащение пульса более чем на $30 \%$ от исходной величины, то сделайте вывод о том, что сердце усиливает свою работу за счет увеличения частоты сокращений. Это означает, что организм тренирован недостаточно. Если дозированная нагрузка не вызывала учащение пульса более чем на $30 \%$ от исходной величины, то сделайте другой вывод: сердце усиливает свою работу за счет увеличения количества крови, выбрасываемого при каждом сокращении. Организм тренирован, и нагрузку можно увеличить [25].

\section{Результативно-оченочный компонент}

Форма предъявления результата: исследовательская работа, доклад и презентация.

Выводы: 1. Физическая нагрузка увеличивает частоту сердечных сокращений и повышает уровень артериального давления. 2. У $32 \%$ учащихся класса сердечная мышца нуждается в тренировке. 
Домашняя работа - проводится для самостоятельного выполнения дома заданий учителя - практических и по учебнику (а также другим источникам информации), связанных с содержанием предыдущих занятий. В рамках данной формы обучения биологии и экологии учащимся можно предложить проследить наследование какого-либо конкретного признака в своей семье и составить родословную. Например, наследование групп крови системы АBO.

\section{Мотивационно-челевой компонент}

Тема исследования: «Наследование групп крови системы АВО в моей семье».

Цель исследования: выявление наследования групп крови системы АВ0 и составление родословной семьи.

Объект исследования: члены семьи.

Предмет исследования: группы крови членов семьи.

Гипотеза исследования: большинство членов семьи имеют вторую группу крови.

\section{Содержательный компонент}

Основные понятия: кровь, группы крови системы AB0, наследование, взаимодействие аллельных генов, множественный аллелизм.

\section{Прочессуальный компонент}

Методы исследования: опрос, составление схемы родословной, генетический анализ.

Материали оборудование: учебник, рабочая тетрадь.

Место проведения: дом.

Форма организации: индивидуальная.

Порядок работы: 1. Опросите членов семьи на предмет их группы крови. 2. Составьте схему родословной. 3. Проанализируйте наследование групп крови в вашей семье. 4. Сделайте вывод о проделанной работе.

\section{Результативно-оченочный компонент}

Форма предъявления результата: схема родословной семьи.

Вывод: у членов семьи присутствуют все группы крови, но преобладают люди со II группой крови.

\section{Зак^ючение}

Рассмотренные выше способы организации учебноисследовательской деятельности учащихся по биологии и экологии будут способствовать формированию у них ценностей научного познания.

\section{ЛИТЕРАТУРА}

1. Федеральный государственный образовательный стандарт основного общего образования / М-во образования и науки Рос. Федерации. М.: Просвещение, 2013. -48 с.

2. Концепция федеральных государственных образовательных стандартов общего образования: проект / Рос. акад. образования; под ред. А.М. Кондакова, А.А. Кузнецова. - М.: Просвещение, 2008. - 39 с.

3. Федеральный государственный образовательный стандарт. Основное общее образование. Проект. - URL: // https://regulation.gov.ru/projects\#npa=94555 (дата обращения: 18.11.2020).

4. Андреева Н.Д., Алексеева Т.Б., Ларченкова Л.А. и др. Формирование научного мировоззрения в процессе естественнонаучного образования школьников: методология исследований, состояние проблемы в теории и практике: коллективная монография / под науч. ред. Н.Д. Андреевой. - СПб.: Изд-во «Свое издательства», 2013. - 182 с.

5. Азизова И.Ю. Формирование ценностных ориентаций у учащихся при обучении биологии в курсе «Человек и его здоровье»: автореф. дис. ... канд. пед. наук. - СПб., 2002. -20 C.

6. Морозова М.И. Формирование научного мировоззрения у учащихся при обучении общей биологии: автореф. дис. ... канд. пед. наук. - СПб., 2005. $18 \mathrm{C}$.

7. Постнова Н.С. Развитие эмоционально-ценностного и интеллектуального компонентов научного мировоззрения у учащихся в процессе обучения биологии (на примере курса «Человек и его здоровье»): автореф. дис. ... канд. пед. наук. - М., 2010. - 24 с.

8. Рябова С.С. Формирование у школьников ценностного отношения к природе в условиях дополнительного образования: автореф. дис. .... канд. пед. наук. - СПб., 2012. -22 с.

9. Семенова Н.Г. Формирование основ биологической картины мира посредством обобщения при обучении учащихся 9-х классов: автореф. дис. ... канд. пед. наук. - М., 2016. -22 c.

10. Чекалова Л.А. Формирование научного мировоззрения учащихся старших классов в условиях гуманитаризации естественно-математических дисциплин: автореф. дис. ... канд. пед. наук. - Карачаевск, 2003. - 24 с.

11. Семенов А.А., Яицкий А.С. Исследовательская деятельность по биологии и экологии как средство формирования научного мировоззрения учащихся: 
научный обзор // Современная наука: актуальные проблемы теории и практики. Серия: Гуманитарные науки. - 2019. - № 10. - С. 93-97.

12. Андреева Н.Д., Азизова И.Ю., Малиновская Н.В. Новые подходы к обучению биологии в общеобразовательной школе в условиях ФГоС: учеб. пособие. СПб.: Изд-во «Свое издательство», 2015. - 299 с.

13. Андреева Н.Д., Азизова И.Ю., Левченко А.Л. Как стать ученым? Рекомендации юным исследователям и их руководителям: учеб. пособие. СПб.: РГПУ им. А.И. Герцена, 2013. - 72 с.

14. Боброва Н.Г. Виды учебно-познавательной деятельности в обучении биологии: дидактическая и методическая характеристика // Самарский научный вестник. - 2014. - № 2 (7). - С. 11-15.

15. Боброва Н.Г. Методика организации учебно-исследовательской деятельности по экологии // Эколого-географические проблемы регионов России: материалы Х всероссийской научно-практической конференции с международным участием, посвящённой 100-летию со дня рождения д.г.н., профессора В.И. Прокаева и 90-летию естественно-географического факультета СГСПУ / отв. ред. И.В. Казанцев. - Самара: СГСПУ, 2019. - С. $379-384$.

16. Всесвятский Б.В. Исследовательский подход к природе и жизни: идеи и практика биостанции юных натуралистов имени К.А. Тимирязева. - М.: Изд-во «Работник просвещения», 1926. -79 с.

17. Ковшар Я.С. Исследовательская деятельность экологического характера во внеурочной работе по биологии» // Globularia: межвузовский сборник научно-исследовательских работ студентов. Вып. 5 / отв. ред. А.А. Семенов. - Самара: СГСПУ, 2018. - С. 165-170.

18. Наливайко И.В., Лаптева Н.В., Рубинова М.Ю. Организация научно-исследовательской деятельности школьников по изучению морфологических и физиологических особенностей грызунов: методические рекомендации для учителей биологии, педагогов дополнительного образования. Самара: Изд-во СГСПУ, 2018. - 40 с.

19. Семенов А.А., Яицкий А.С., Панфилова Л.В., Павловский В.А. Организация учебно-исследовательской деятельности учащихся биоэкологической направленности // Самарский научный вестник. - 2018. - Т. 7, № 4 (25). - С. 352-360.

20. Суматохин С.В. Требования ФГОС к учебно-исследовательской и проектной деятельности // Биология в школе. - 2013. - № 5. - С. 60-68.

21. Суматохин С.В. Учебно-исследовательская деятельность по биологии в соответствии с ФГОС: с чего начать, что делать, каких результатов достичь // Биология в школе. - 2014. - № 4. - С. 23-29.

22. Тяглова Е.В. Исследовательская и проектная деятельность учащихся по биологии: метод. пособие. - М.: Глобус, 2008. - 255 с.

23. Ясюк В.П. Технологии учебно-исследовательской деятельности учащихся: метод. пособие. - Самара: МБОУ ДОД ЦДОД «Искра» г.0. Самара, 2013. - 40 с.

24. Семенов А.А., Боброва Н.Г., Глазкова Л.М. Вопросы теории и методики обучения биологии: учеб. пособие для студентов-заочников. - Самара: Изд-во СГПУ, 2003. - 175 C.

25. Воронин Л.Г., Маш Р.Д. Методика проведения опытов и наблюдений по анатомии, физиологии и гигиене человека: кн. для учителя. - М.: Просвещение, 1983. -160 c.

26. Пономарева И.Н., Роговая О.Г., Соломин В.П. Методика обучения биологии: учебник для студ. учреждений высш. проф. образования / под ред. И.Н. Пономаревой. - М.: Издательский центр «Академия», 2012. - 368 с.

27. Семенов А.А. Экология. Краткий курс: учебное пособие для учащихся старших классов. - Самара: Изд-во СГСПу, 2003. - 129 с.

28. Полевой практикум по теории и методике обучения биологии: учебно-методическое пособие для студентов-заочников / авт.-сост.: Л.И. Лушина, А.А. Семенов, Н.Г. Боброва и др.; под ред. А.А. Семенова. - Самара: Изд-во СГПУ, 2004. - 85 с.

(c) Семенов Александр Алексеевич (semenov@sgspu.ru), Яицкий Андрей Степанович (yaitsky@sgspu.ru).

Журнал «Современная наука: актуальные проблемы теории и практики» 